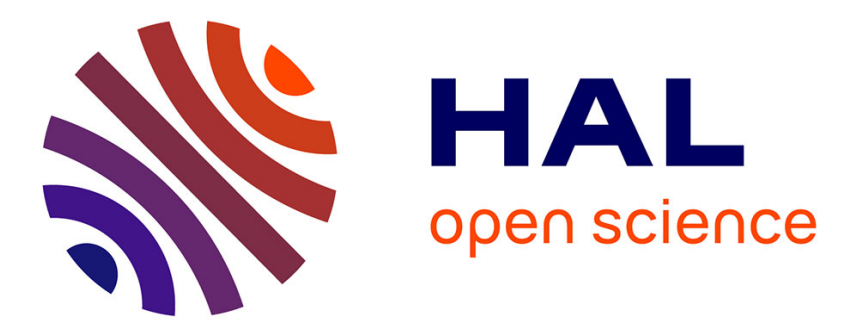

\title{
Business Analytics in Production Management - Challenges and Opportunities using Real-World Case Experience
}

\author{
Andrea Kö, Tibor Kovacs
}

\section{- To cite this version:}

Andrea Kö, Tibor Kovacs. Business Analytics in Production Management - Challenges and Opportunities using Real-World Case Experience. 22nd Working Conference on Virtual Enterprises (PROVE 2021), Nov 2021, Saint-Etienne, France. pp.558-566, 10.1007/978-3-030-85969-5_52 . emse03346499

\section{HAL Id: emse-03346499 \\ https://hal-emse.ccsd.cnrs.fr/emse-03346499}

Submitted on 25 Nov 2021

HAL is a multi-disciplinary open access archive for the deposit and dissemination of scientific research documents, whether they are published or not. The documents may come from teaching and research institutions in France or abroad, or from public or private research centers.
L'archive ouverte pluridisciplinaire HAL, est destinée au dépôt et à la diffusion de documents scientifiques de niveau recherche, publiés ou non, émanant des établissements d'enseignement et de recherche français ou étrangers, des laboratoires publics ou privés. 


\title{
Business Analytics in Production Management - Challenges and Opportunities using Real-World Case Experience
}

\author{
Andrea Kő and Tibor Kovács \\ Corvinus University of Budapest, Fővám tér 8, Budapest, Hungary \\ \{andrea.ko, tibor.kovacs\}@ uni-corvinus.hu
}

\begin{abstract}
Data is a key component of smart manufacturing coming from various sources and in different forms. The amount of data produced in the Manufacturing Data Life Cycle (MDLC) could be vast and remain useless if not processed and mapped into information that is understood by users. Because of the data volume, velocity, variety, and veracity, it is not feasible to expect humans to analyze it using traditional manufacturing tools; business analytics solutions provide more efficient means. In this paper, first, we aim at identifying the latest research areas and trends of business analytics (BA) in the production management (PM) literature using text mining, bibliometric mapping, and visual analytics. We discuss the related research gaps, BA challenges and problems and give suggestions for possible BA applications and future research directions. Second, we selected the performance management and decision-making cluster for presenting a real-world case and we applied MDLC as a framework. The case study presents a big data analytics performance monitoring system from a multiproduct refinery.
\end{abstract}

Keywords: business analytics, production management, Manufacturing Data Life Cycle, data-driven decision making, performance management.

\section{Introduction}

Data is a key component of smart manufacturing coming from various sources and in different forms. The amount of data produced in the Manufacturing Data Life Cycle (MDLC) could be vast and remain useless if not processed and mapped into information that is understood by users. Because of the data volume, velocity, variety, and veracity, it is not feasible to expect humans to analyze it using traditional manufacturing tools; business analytics solutions provide more efficient means. The "information age [1]" has laid the foundation of information technologies, that capitalize on manufacturing data for business analytics and process monitoring. Smart manufacturing however delivered the supplementary technologies that were required to handle data in larger quantities, from diverse sources and in disparate formats and to accomplish significantly more complex data transformations and analysis for more responsive decision making. There are numerous challenges related to data driven performance monitoring: vast quantity of data, diverse sources, questionable data quality, ongoing 
use of legacy systems and the absence of strong analytics culture. This latter means that data is not perceived as a core asset of the organization, senior management is not leading the organization to become more data-driven and analytical, and the organization is not using analytical insights to guide strategy [2]. We examine how the new business analytics technologies, and a strong analytics culture could contribute to production management, performance monitoring and performance improvements in the manufacturing environment.

In this paper, we have two goals. First, we aim at identifying the latest research areas and trends of business analytics (BA) in the production management (PM). From methodological aspects we followed the steps of systematic literature review combined with text mining, bibliometric mapping, and visual analytics (we discuss the methodological steps in section 2.1). As a result, we got research areas, clusters, which are worth to investigate. We detail the related research gaps, BA challenges and problems and give suggestions for possible BA applications and future research directions. Second, we selected the performance management and decision-making cluster for presenting a real-world case and we applied Manufacturing Data Life Cycle as a framework. The case study presents a big data analytics performance monitoring system from a multi-product refinery. The contribution of our research is the following: 1) identification the latest research areas and trends of $B A$ in production management based on the literature 2) discussion of research gaps, BA challenges and problems; providing suggestions for possible BA applications and future research directions 3) demonstrate and connect our findings through a real-world case performance monitoring solution.

\section{Business Analytics in Production Management - Literature Review}

The term "business analytics" was introduced to represent the key analytical components of business intelligence in the late 2000s [3]. Chen, Chiang and Storey [4] distinguish 3 phases in the history of business intelligence and analytics (BI\&A), denoted as BI\&A 1.0, 2.0, and 3.0 according to Gartner BI reports on platforms' core capabilities and the hype cycle. Data management and data warehousing is considered as the foundation of BI\&A 1.0, BI\&A 2.0 bringing in text and web analytics capabilities for unstructured contents, using web intelligence and the analysis of user-generated content. BI\&A 3.0 is opening new opportunities by utilizing data from mobile devices and their complete ecosystems, as well as from sensor-based Internet-enabled devices equipped with RFID, barcodes, and radio tags (the "Internet of Things"). Business analytics covers descriptive analytics (what is happening), predictive analytics (what will happen next) and prescriptive analytics (what is the best course for the future) [5]. Business analytics applies various advanced analytic techniques answering questions or solve problems related to business [6]. Isasi et al. [7] surveyed the literature of big data and business analytics applications in the supply chain using bibliometrics and systematic analysis. Zhang and Chen [8] provides a comprehensive review of the recent research on Industry 4.0, IoT, Blockchain, and Business Analytics. 


\subsection{Literature Review - Methodology and Preliminary Results}

Our literature review approach is split into two phases. First, we collected the relevant articles from Scopus to prepare a corpus of BA in PM domain, and analyzed these articles using text mining, bibliometric mapping, and visual analytics. Second, using the results from the first phase and combining it with our own experience in the field, we extended the analysis to potential research challenges, directions and relevant BA solutions using a more detailed and focused discussion.

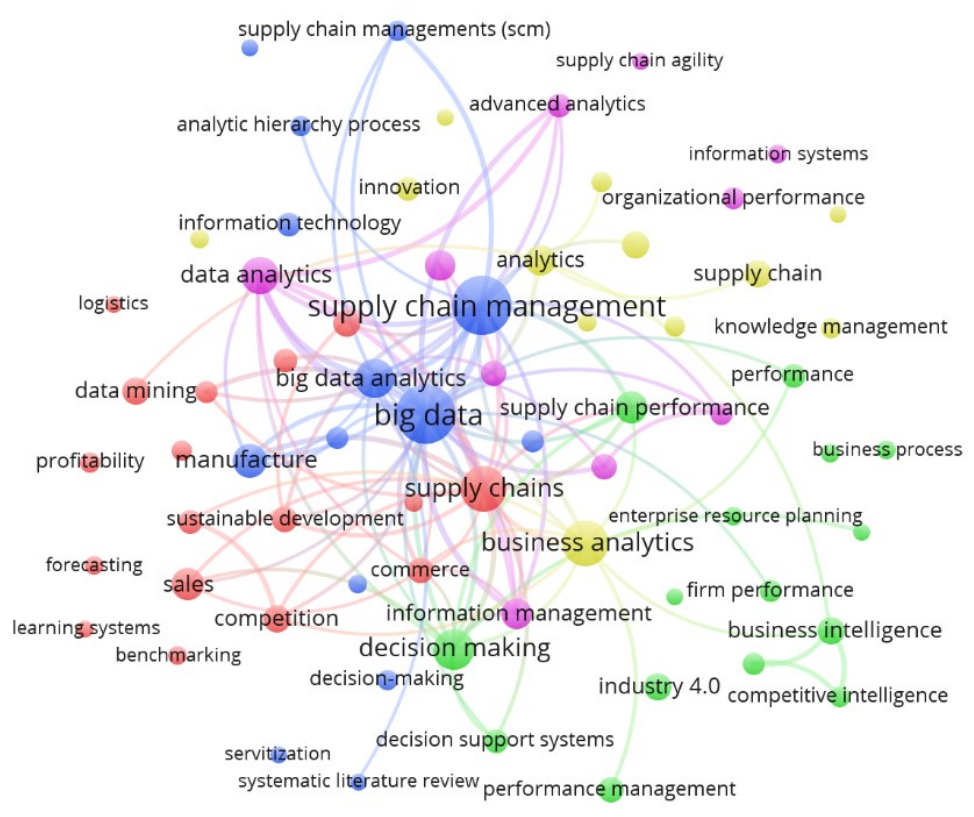

performance measurement

Fig. 1. Bibliometric mapping and text mining of business analytics articles with VOSviewer ${ }^{1}$

Preparing the corpus for text mining, we focused on papers from Scopus with primary keywords of "business analytics" and "production management", resulting to 314 articles (up to December 2020). We tested Web of Science as an alternative source but discarded it due to their limited number of articles (less than 50 papers). To explore the main research areas of BA in PM, we clustered the articles with VOSviewer bibliometric mapping and text mining solution [9] and described the clusters using the most compelling keywords (Fig. 1).

\footnotetext{
${ }^{1}$ The Figure is an illustration it doesn't contain all concepts' labels.
} 
Table 1. Research Areas/Clusters of Business Analytics in Production Management Corpus

\begin{tabular}{|l|l|l|l|}
\hline $\begin{array}{l}\text { Research area/ } \\
\text { Cluster name }\end{array}$ & $\begin{array}{l}\text { Keywords describing the } \\
\text { research domain }\end{array}$ & $\begin{array}{l}\text { Keywords describing } \\
\text { business analytics } \\
\text { characteristics }\end{array}$ & $\begin{array}{l}\text { Research Challenges, } \\
\text { Directions and Opportunities } \\
\text { from BA viewpoints }\end{array}$ \\
\hline $\begin{array}{l}\text { sustainable and } \\
\text { competitive } \\
\text { supply chain }\end{array}$ & $\begin{array}{l}\text { competition } \\
\text { resource-based view } \\
\text { competitive advantage } \\
\text { sustainability } \\
\text { supply chains } \\
\text { sustainable development }\end{array}$ & $\begin{array}{l}\text { predictive analytics } \\
\text { data mining } \\
\text { regression analysis } \\
\text { learning systems }\end{array}$ & $\begin{array}{l}\text { How to process unstructured } \\
\text { data produced in a supply } \\
\text { chain (e.g., log file, image, } \\
\text { data from sensors) This } \\
\text { field is usually not included } \\
\text { to predictive analytics, but } \\
\text { most data produced in this } \\
\text { category. }\end{array}$ \\
\hline $\begin{array}{l}\text { performance } \\
\text { management and } \\
\text { decision making }\end{array}$ & $\begin{array}{l}\text { supply chain } \\
\text { performance } \\
\text { industry 4.0 } \\
\text { performance } \\
\text { firm performance } \\
\text { performance } \\
\text { management }\end{array}$ & $\begin{array}{l}\text { decision support } \\
\text { systems } \\
\text { decision making }\end{array}$ & $\begin{array}{l}\text { Which BA tools support } \\
\text { problem solving process, } \\
\text { cause effect analysis } \\
\text { correlation and optimization? }\end{array}$ \\
\hline $\begin{array}{l}\text { big data } \\
\text { analytics }\end{array}$ & $\begin{array}{l}\text { supply chain } \\
\text { management } \\
\text { industrial research }\end{array}$ & $\begin{array}{l}\text { big data } \\
\text { big data analytics }\end{array}$ & $\begin{array}{l}\text { Which BA applications to } \\
\text { apply, what are the related } \\
\text { conditions? }\end{array}$ \\
\hline $\begin{array}{l}\text { knowledge and } \\
\text { information } \\
\text { management }\end{array}$ & $\begin{array}{l}\text { innovation } \\
\text { knowledge management } \\
\text { information management } \\
\text { enterprise resource } \\
\text { management }\end{array}$ & $\begin{array}{l}\text { supply chain analytics } \\
\text { data analytics }\end{array}$ & $\begin{array}{l}\text { How to map and store } \\
\text { domain knowledge and } \\
\text { which is the way of } \\
\text { application of domain } \\
\text { knowledge in BA solutions? }\end{array}$ \\
\hline
\end{tabular}

The analysis resulted to five clusters, however due to the similarity of the fourth and fifth clusters, both related to knowledge, information management and business analytics were combined. Table 1 details the research areas defined by the clusters, their domain, and their BA related keywords, as well as the research challenges, directions, and opportunities from BA viewpoints. Our view is that the key challenges are the following: 1) predictive analytics and data mining require developing methods to process unstructured data produced in a supply chain, 2) business intelligence and decision support systems need developing and implementing BA tools to support the problem solving process, cause effect analysis, correlation and optimization, 3) big data analytics need developing BA applications and that take into consideration production specific conditions, and finally 4) supply chain data analytics poses the challenge of how to map and store domain specific knowledge and which is the way of applying this domain knowledge in BA solutions.

\subsection{Business Analytics Problems and Challenges in the Manufacturing Data Life Cycle}

The aim of this section is to identify the typical BA problems and challenges related to 
the phases of MDLC. We use MDLC of Tao et al. [1] as a discussion framework to connect the research challenges identified in the literature review, from our experience and the issues revealed from our real-world case (Fig. 2). Data in a manufacturing environment is collected from numerous sources in a variety of ways, that can be structured (e.g., databases), semi-structured (e.g., XML documents), or unstructured (e.g., textual information from equipment and error logs) [10]. Data processing starts with the pre-processing steps of data cleaning and data reduction; it is usually a complex and non-trivial operation. In the manufacturing environment, missing values are common, and they pose a challenge to the application of machine learning algorithms [11].

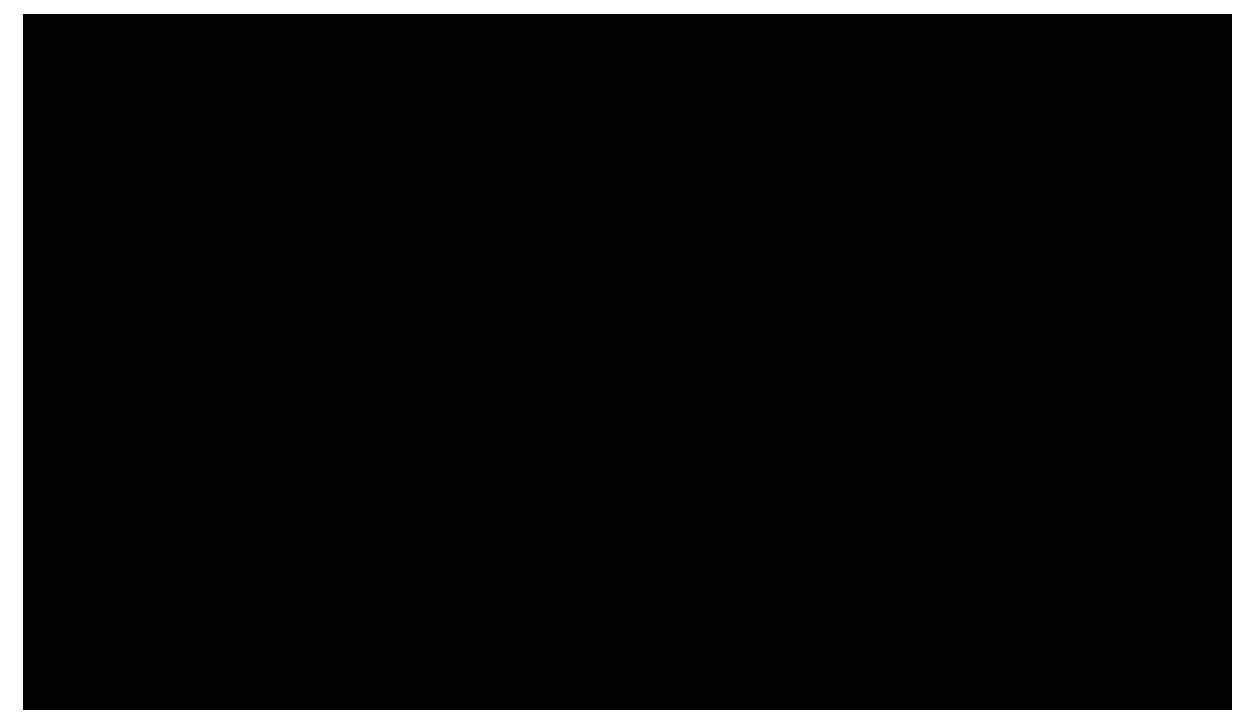

Fig. 2. Business analytics challenges using Manufacturing Data Life Cycle MDLC [1].

Data reduction transforms the massive volume of data into ordered, meaningful, and simplified forms, followed by data analysis covering a wide variety of techniques, including machine learning, data mining, time-series analysis, large-scale computing, and the use of forecasting models. Visual analytics and visualization support the communication with end users, it helps having a clear, user-friendly view of the data and an easy understanding the data processing results [12].

Tao et al. [1] distinguished three types of data applications: The first (design) helps in demand analysis, smart design, and market forecasting through better understanding of customers, competitors, and markets. The second (manufacturing) supports decision making, product quality control and equipment supervision. The third phase (MRO maintenance, repair, and operations) enriches monitoring operations, fault predictions and smart maintenance. These data applications can lead to informed decisions concerning whether, when, and how to adjust the manufacturing processes and equipment, and how to facilitate the control and improvement of product quality, yield, or energy usage. 


\section{Business Analytics Problems and Challenges from a Real-World Case}

We utilize experiences collected in a real-world case to discuss the business analytics problems and challenges in production management. The case is from a large multiproduct refinery that has recently implemented a performance monitoring system using big data analytics. Management was driving the implementation to sustain the previously achived annual performance improvements of over $10 \%$ per year in several areas like energy efficiency, yields and volumes; and to make the operation more secure for the long run. The plant applies World Class Manufacturing methodology, of which visual performance management (VPM) is a key component. VPM helps improving internal and external communication, facilitates performance measurement and review, enhances collaboration and supports the cultural change [13]. The system was developed with the desire to use existing data sources, demonstrate compliance to performance standards, visualize performance trends and assist with performance improvement initiatives as a diagnostics tool. The case was specifically selected as the plant posessed large number of Industrial IoT sensors, however the utilisation of data from these sensors were sporadic and ad-hoc. It was therefore interesting to explore how a business analytics system could add value to this installation.

\subsection{Background on the Case}

The plant had high levels of process control with state-of-the-art automation, Industrial IoT process measurement and data storage, recording numerical values of process parameters (e.g. flow rates, temperatures, pressures) and also alarm and error logs. Laboratory results were collected using Excel workbooks, being migrated to a Laboratory Information Management System (LIMS). Maintenance records were stored in a Computerized Maintenance Management System, recording equipment failures, repair and restoration activities as well as predictive maintenance related data. This broad range of separate systems made it difficult the concurrent analysis of data from different sources, limiting process optimisation efforts (Fig. 3).

The project started by reviewing existing key performance indicators and performance metrics, defining new ones, with the desire to get an integrated, holistic view on business performance. Both lead and lag indicators [14] were used in the final set, the former being proactive, preventive and predictive while the latter displaying the final outcome. Process parameters like temperature, pressure, flow rate were often used as lead indicators supporting the process optimisation efforts: setting the optimal parameter values and using process control to ensure the adherence to those set values. 


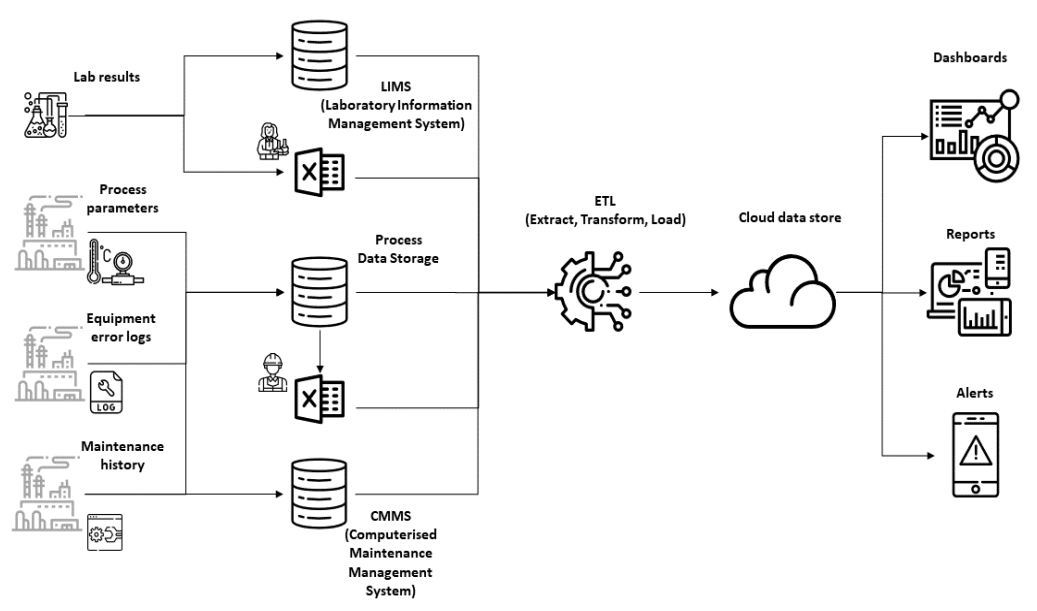

Fig. 3. Performance monitoring system architecture using big data.

\subsection{Challenges to Implement Business Analytics in the Real-World Case}

Design science methodology for information systems [15] was used for investigating the problems and challenges of performance monitoring and business analytics solutions in relation to the MDLC phases. The case showed that with the currently available business analytics tools, a performance monitoring solution could be relatively quickly developed, demonstrating the value of data-driven decision making. The amount of data stored in the system was rather a burden than an advantage; finding the appropriate information of process parameters among the ones that were recorded required the thorough knowledge of system. It requires the careful selection of those that objects that are connected to key performance indicators. Data quality poses a serious threat to the success of such projects, often realised only after the project is underway. Structural errors (format errors, typos) could break the data extraction, transformation and load (ETL) process, while missing data and outliers would result to implausible results, making visualizations meaningless. The ETL process therefore must be prepared for both the initial cleansing and the ongoing data quality issues [16]. The benefit of such an automated system over a manual system is enabling real time data processing and alerting, flexible analysis of larger data sets, from disperate sources and better supporting problem soving and decision making by cause and effect analysis. However, the case drew the attention to the fact, that taking advantage of this would require a strong analytics culture. A key success factor of such an initiative is a commitment from management, encouraging the use of analytics and data-driven decision making, and developing the human analytical competence. 


\section{Conclusion}

Our investigation of the real-world performance monitoring and business analytics solution in the context of the MDLC of Tao et al. [1] resulted to the following findings: The divers data sources in manufacturing, often with questionable data quality poses some serious challenge to the success of developing a business analytics solution. Missing data and outliers, often related to the unreliability of field equipment makes especially difficult data aggregation, requiring foresigh and sound business logic. The data collection requires skills in both industrial and business systems as data sources. Regarding data storage, there are limitations and security concerns of storing data in the cloud. On premises data storage therefore could be a requirement to overcome these problems. The data processing would require the appropriate selection of models, including text mining methods for processing alarm and error logs. The amount of data from IoT sensors would require data reduction, to enable processing it over a longer period. Dashboards should facilitate performance review and problem solving, chosing the right visualizations for different metrics and performance indicators. Finally, Specific business analytics applications should be selected based on key performance indicators that could vary from simple dashboards to complex machine learning models. Our investigation highlighted, that the lack of business analytics skills and analytics culture could be a barrier to success. It needs to be developed simultaneously with the development of the performance monitoring and business analytics solution.

\section{References}

1. Tao, F., Qi, Q., Liu, A., Kusiak, A.: Data-driven smart manufacturing. Journal of Manufacturing Systems 48,157-169. https://doi.org/10.1016/i.jmsy.2018.01.006 (2018)

2. Kiron, D., Prentice, PK., Ferguson, RB.: The Analytics Mandate. MIT Sloan Management Review 55, 1-25 (2014)

3. Davenport, TH.: Competing on analytics. Harvard Business Review 84 (2006)

4. Chen, H., Chiang, RHL., Storey, VC.: Business intelligence and analytics: From big data to big impact. MIS Quarterly: Management Information Systems 36, 1165-1188 (2012)

5. Stubbs, E.: The value of business analytics: Identifying the path to profitability. John Wiley \& Sons (2011)

6. Trkman, P., McCormack, K., de Oliveira, MPV., Ladeira, MB.: The impact of business analytics on supply chain performance. Decision Support Systems 49, https://doi.org/10.1016/j.dss.2010.03.007 (2010)

7. Gimenez, Isasi, NK., Morosini Frazzon, E., Uriona, M.: Big Data and Business Analytics in the Supply Chain: A Review of the Literature. IEEE Latin America Transactions 13, https://doi.org/10.1109/TLA.2015.7387245 (2015)

8. Zhang, C., Chen, Y.: A Review of Research Relevant to the Emerging Industry Trends: Industry 4.0, IoT, Blockchain, and Business Analytics. Journal of Industrial Integration and Management 05, https://doi.org/10.1142/S2424862219500192 (2020)

9. van Eck, NJ., Waltman, L.: Software survey: VOSviewer, a computer program for bibliometric mapping. Scientometrics 84, 523-538, https://doi.org/10.1007/s11192-0090146-3 (2010)

10. Gandomi, A., Haider, M.: Beyond the hype: Big data concepts, methods, and analytics. International Journal of Information Management 35, 137-144. 
https://doi.org/10.1016/j.ijinfomgt.2014.10.007 (2015)

11. Pham, DT., Afify, AA.: Machine-learning techniques and their applications in manufacturing. Proceedings of the Institution of Mechanical Engineers, Part B: Journal of Engineering Manufacture 219, 395-412 https://doi.org/10.1243/095440505X32274 (2005)

12. Kovács, T., Kö, A.: Machine Learning Based Monitoring of the Pneumatic Actuators' Behavior Through Signal Processing Using Real-World Data Set. In: International Conference on Future Data and Security Engineering, pp. 33-44. Springer, Cham. https://doi.org/10.1007/978-3-030-35653-8 3 (2019)

13. Bititci, U., Cocca, P., Ates, A.: Impact of visual performance management systems on the performance management practices of organisations. International Journal of Production Research 54, 1571-1593 https://doi.org/10.1080/00207543.2015.1005770 (2016)

14. Anderson, K., McAdam, R.: A critique of benchmarking and performance measurement: Lead or lag? Benchmarking 11, 465-483 https://doi.org/10.1108/14635770410557708 (2004)

15. Wieringa, RJ.: What Is Design Science? In: Design Science Methodology for Information Systems and Software Engineering. pp. 3-11. Springer Berlin Heidelberg, Berlin, Heidelberg (2014)

16. Marsh, R.: Drowning in dirty data? It's time to sink or swim: A four-stage methodology for total data quality management. Journal of Database Marketing \& Customer Strategy Management 12, 105-112. https://doi.org/10.1057/palgrave.dbm.3240247 (2005) 